\title{
Experiment on the Negative Friction of Single Pile under Self-weight Consolidation for the Dredger Fill
}

\author{
Ping Yang ${ }^{1, a}$, Shoubao Xue ${ }^{1, b}$, and Yaohui Liu ${ }^{1, ~ c, *}$ \\ ${ }^{1}$ Department of Geotechnical Engineering, College of Civil Engineering, Tongji University, \\ Shanghai 200092, China; \\ a Pingyang@tongji.edu.cn, b523345909@qq.com, ${ }^{b}$ liuyaohui@tongji.edu.cn
}

Keywords: dredger fill; pile; negative friction; centrifugal model test; self-weight consolidation

\begin{abstract}
The objective of this paper is to analyze the negative friction of pile caused by the self-weight consolidation of dredger fill. It is difficult for routine test to meet the time requirement of self-weight consolidation of soil. However, the centrifugal test model adopted the scale-shrink effect and the model satisfied the requirement of pile-soil consolidation in a short time. Thus the self-weight consolidation of the dredger fill at the upper part of the single pole foundation in the soft soil was simulated by the centrifugal model test. The result of the experiment showed that when the self-weight consolidation of dredger fill sustained for 2.5, 20, 50 months, the negative friction was $85.6 \%, 52.67 \%, 20.65 \%$ of the pile top load. The negative friction disappeared when the self-weight consolidation sustained for 75 months. The relationship between pile-soil settlement and time corresponds with the Hill Model. It is feasible to forecast the pile-soil settlement of the self-weight consolidation of stacking dredger fill through the Hill Model.
\end{abstract}

\section{Introduction}

Dredger fill is used to backfill the clay frequently in the harbor engineering when the pile foundation cuts across the clay layer and embeds the hard sand layer, as shown in figure1 (a) [1]. The clay becomes over consolidated under the stress of numerous stacking dredger fill. Degree fill will also consolidate under its self-weight, as shown in figure 1 (b) [2-3].It will cause Negative skin friction (NSF) on the pile as the soil settlement is greater than the pile settlement. NSF causes the drag load and affect the normal use of the pile foundation.

NSF of piles could be analyzed through the theoretical analysis [4-5], laboratory tests [6-9] and site tests [10-11]. Abdrabbo [12] acquired the effect of pile top load and soil layer additional load through three-dimensional nonlinear analysis. Kong [13] acquired the results that when the relative displacement reaches to $2 \mathrm{~mm}$, the negative friction account for $75-95$ percent of the maximum and the neutral surface becomed steady when the consolidation time was 240 hours through model tests and numerical analysis. Hong [14] discovered that the depth of neutral point of drilled pile equaled to 
0.04-0.06H ( $\mathrm{H}$ was the thickness of clay layer).

It takes a long time to finish the self-weight consolidation for dredger fill [15]. It is difficult for routine tests to meet the time requirement of self-weight consolidation. However, the centrifugal test model adopted the scale-shrink effect and the model satisfied the requirement of pile-soil consolidation in a short time. Therefore, NSF of piles caused by the self-weight consolidation of dredger fill was conducted by centrifugal model tests. The development of lateral friction of piles in dredger fill was analyzed.

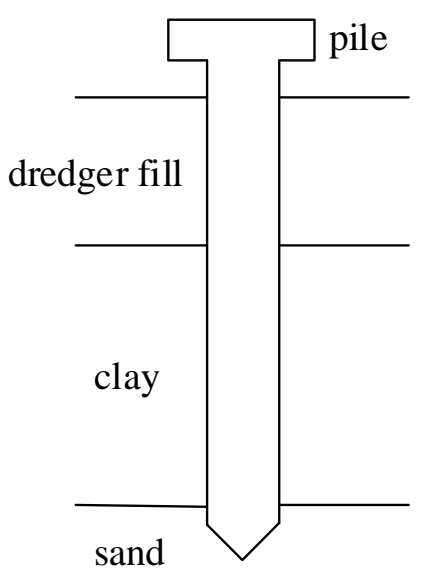

(a)

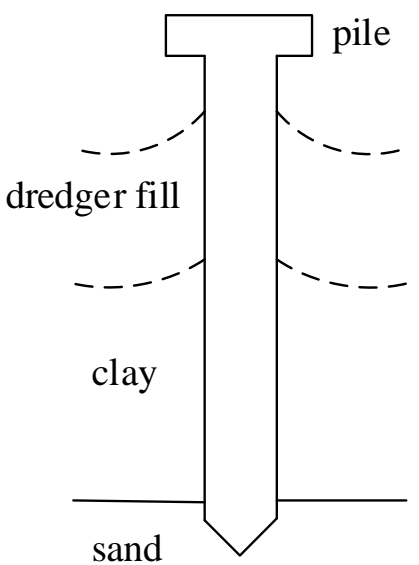

(b)

Fig. 1 The schematic diagram of generation of negative friction of pile function.

\section{Methods}

Tests were conducted at TLJ-150 centrifugal machine in Tongji laboratory. The maximum acceleration was $200 \mathrm{~g}$. The effective radius was $3.0 \mathrm{~m}$ and the peak load was $1.5 \mathrm{t}$.

\subsection{Section headings}

According to the similarity criterion of geotechnical centrifuge model, the character and the stress state of centrifugal model tests must be identical with prototype. The similarity criterion of centrifugal model is Eq. (1). $\mathrm{n}$ is model rate.

$$
\mathrm{g}_{\mathrm{m}}=\mathrm{n} \cdot \mathrm{g}_{\mathrm{p}}
$$

It shows that if the strength of model narrow $n$ times, the gravitational acceleration ( $g m$ ) of model must be as $n$ times large as gravitational acceleration of prototype on the condition that the character of model is identical with prototype.

\subsection{Experimental model}

The length $\backslash$ width height of the test model is $0.6 \mathrm{~m} \backslash 0.4 \mathrm{~m} \backslash 0.28 \mathrm{~m}$ and the length $\backslash$ width $h$ height of the prototype is $45 \mathrm{~m} \backslash 30 \mathrm{~m} \backslash 21 \mathrm{~m}$; the height of model pile is $25 \mathrm{~cm}$ and the external diameter is $20 \mathrm{~mm}$, $16 \mathrm{~mm}, 14 \mathrm{~mm}$. The thickness of aluminum-alloy pipe is $1 \mathrm{~mm}$. On the other hand, the length of prototype is $16.25 \mathrm{~m}$. The external diameter is $1.5 \mathrm{~m}, 1.2 \mathrm{~m}, 1.05 \mathrm{~m}$ and the inner diameter is $1.5 \mathrm{~m}, 1.2 \mathrm{~m}$, $1.05 \mathrm{~m}$; the model boundary is steel plate with $50 \mathrm{~mm}$ thickness. The soil of the model was sampled from Shanghai Lin-gang and its properties are shown in Table 1. The basic physical and mechanical properties are shown in Table 2: 
Table 1 Particles content of degree fill and clay

\begin{tabular}{cccc}
\hline Grain composition & Dredger fill/\% & Silt/\% & Silty sand/\% \\
\hline $0.25-0.074 \mathrm{~mm}$ & 8.8 & 31.6 & 62.9 \\
$0.074-0.005 \mathrm{~mm}$ & 79.1 & 62.6 & 32.1 \\
$<0.005 \mathrm{~mm}$ & 12.1 & 5.8 & 5.0 \\
\hline
\end{tabular}

Table 2 Basic physical and mechanical properties of foundation soil

\begin{tabular}{ccccc}
\hline Description & Dredger fill & Clay & Silt & Silty sand \\
\hline density/g/cm3 & 1.85 & 1.74 & 1.86 & 1.90 \\
moisture content/\% & 32.2 & 43.3 & 30.4 & 26.6 \\
void ratio & 1.10 & 1.22 & 0.86 & 0.76 \\
proportion/g/cm3 & 2.71 & 2.75 & 2.70 & 2.69 \\
internal friction angle/ & 29 & 13 & 33 & 35 \\
cohesion/kPa & 11 & 14 & 7 & 4 \\
compressibility factor & 0.24 & 0.80 & 0.14 & 0.09 \\
Plastic limit & & 21.3 & & \\
liquid limit & & 0.84 & & \\
\hline
\end{tabular}

\subsection{Measure of test data}

The deformation of pile was measured with strain gage and the method is half-bridge. The displacement of soil was measured by LVDT and pre-embed the settlement-pole in the layer, as shown in Fig. 2.
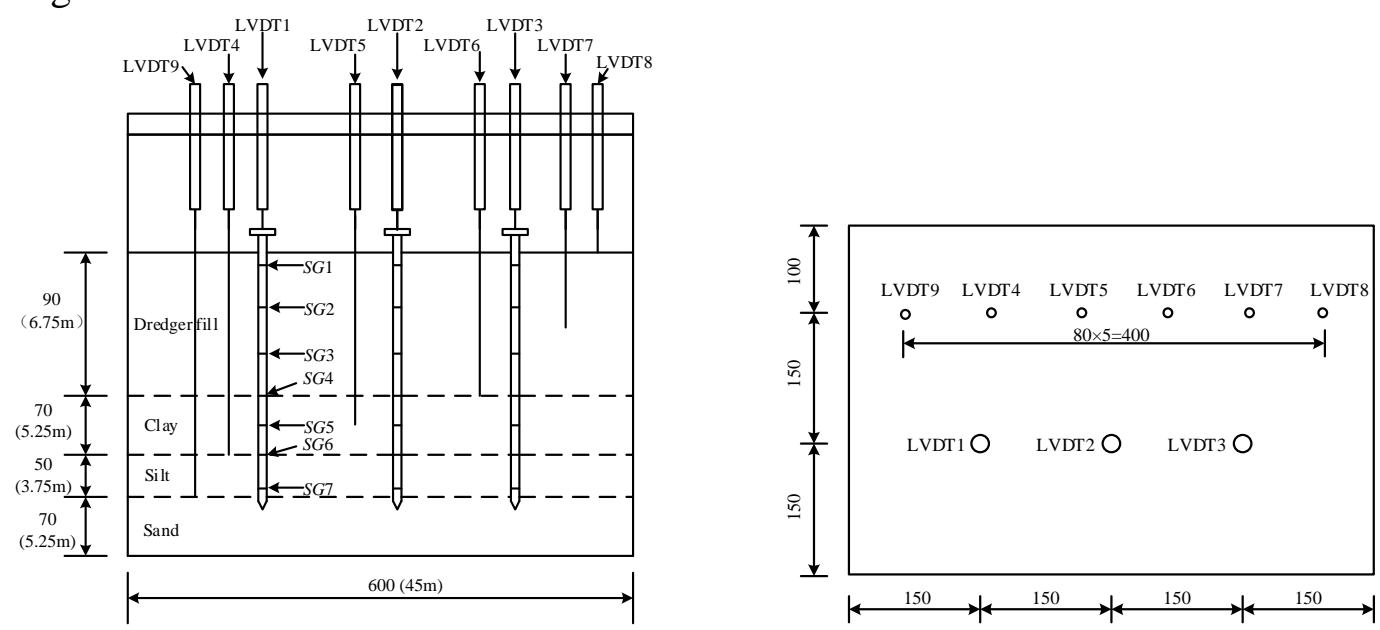

Fig.2 Schematic diagram of model test. (unit:mm)

\subsection{Modeling}

Working process of the pile-soil test model: (1) calculate the weight of dry soil and water of each layer according to the scale of model box; (2) stir the homogeneous soul and throw it to the model box with uniform velocity. The thickness of each turn shouldn't pass $2 \mathrm{~cm}$. Start the next turn from the opposite direction until it reaches to the design height. (3) sustain for 2 hours and wait for saturation after each layer of soil is finished. (4) bury the settling-pole at the designed location;(5) operate the centrifugal machine for 8 hours with the accelerated velocity of 75g. Close machine when the degree of consolidation of layer reaches to $90 \%$; (6) throw fill the dredger fill with the accelerated velocity of 1g. Repeat the procesure1-4; (7) install the single-pole at the accelerated velocity of $1 \mathrm{~g}$. Insert the pole 
into 1.5D depth of the sand ( $\mathrm{D}$ is radius of pole). Finally insert the single-pole into the designated spot through the piling equipment with the velocity of $0.5 \mathrm{~mm} / \mathrm{s}$ (8) Install cushion cap and load the design load of experiment. Simultaneously, install the measuring transducer, as shown in Fig. 3.

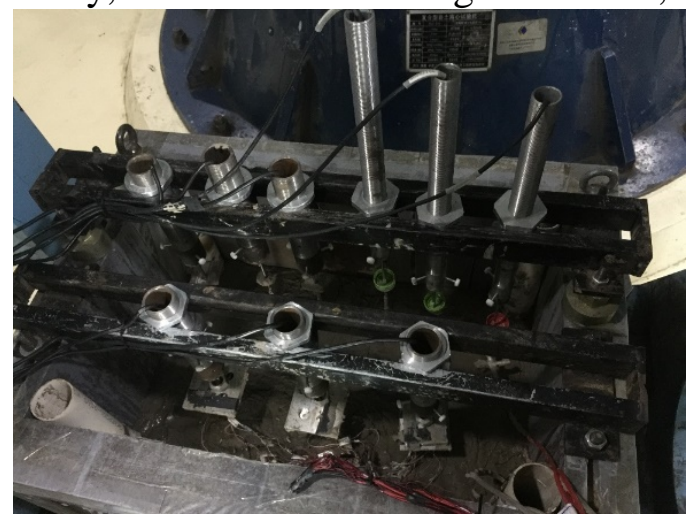

Fig. 3 Pile-soil centrifuge test model

\subsection{Experimental scheme}

Vertical stress of $157.60 \mathrm{t}, 126.08 \mathrm{t}, 110.32 \mathrm{t}$ is loaded on the single pile cap with the radium of 1.5 $\mathrm{m}, 1.2 \mathrm{~m}, 1.05 \mathrm{~m}$ respectively. According to the similarity principle, the weight of $0.374 \mathrm{~kg}, 0.299 \mathrm{~kg}$, $0.261 \mathrm{~kg}$ should be loaded on the single pile cap with the radium of $20 \mathrm{~mm}, 16 \mathrm{~mm}, 14 \mathrm{~mm}$.

Fix the model on the centrifugal machine and adjust the accelerated velocity as $75 \mathrm{~g}$ for 8 hours after the single-pile installation is finished. The operation of centrifugal machine: (1) make sure every sensor is normal working and collecting data automatically with the period of 1s (2) The accelerated velocity starts from $0 \mathrm{~g}$ and come up to $75 \mathrm{~g}$ after 5 minutes;(3) Steady operation with the accelerated velocity of $75 \mathrm{~g}$ for 8 hours;(4) Stop the collect data automatically when the centrifugal machine stops.

\section{Results}

\subsection{Consolidation settlement of pole-soil}

According to the similarity principle, the consolidation settlement of pole-soil of prototype is shown in the Table 3 . The condition of above calculation is that the accelerated velocity of centrifugal machine reach to $75 \mathrm{~g}$ and dredger fill self-weight consolidates for 8 hours. The Table 3 shows that the sediment of silt is less than the sediment of single-pile and the sediment of dredger fill is larger than the sediment of single-pile.

Table 3 Sediment of pile-soil

\begin{tabular}{ccccccc}
\hline & \multicolumn{2}{c}{ Sediment of layer $/ \mathrm{mm}$} & \multicolumn{3}{c}{ Sediment of single pile $/ \mathrm{mm}$} \\
\hline layer & thickness/mm & model $/ \mathrm{mm}$ & prototype/mm & Single-pile & model/mm & petrotype/mm \\
\hline LVDT8 & 30 & 6.548 & 491.100 & radius20 & 0.641 & 48.075 \\
LVDT7 & 30 & 4.137 & 310.275 & radius16 & 0.661 & 49.575 \\
LVDT6 & 35 & 2.729 & 204.675 & radius14 & 0.681 & 51.075 \\
LVDT5 & 35 & 1.351 & 101.325 & & & \\
LVDT4 & 50 & 0.736 & 55.225 & & & \\
LVDT9 & 70 & 0.319 & 23.925 & & & \\
\hline
\end{tabular}




\subsection{Relationship between the consolidation of pile-soil and time}

The relationship between sediment of prototype and time through the similarity principle is shown in figure4.

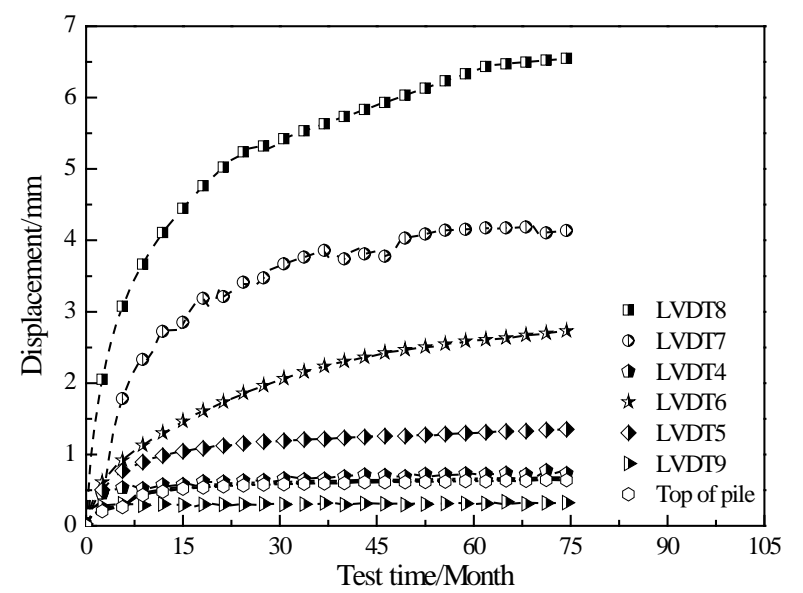

Fig. 4 Relationship between settlement of pile-soil

The result shows that the relationship between sediment of layer, sediment of pile and time is appropriate for Hills model [15]:

$$
s_{t}=s_{t m} \frac{t^{\lambda}}{t^{\lambda}+k^{\lambda}}
$$

Where $\mathrm{s}_{\mathrm{t}}$ is the displacement of pile and soil at any time, $\mathrm{mm}$; $\mathrm{s}_{\mathrm{tm}}$ is the maximum settlement value of soil and pile, $\mathrm{mm}$; $\mathrm{t}$ is the time of consolidation, $\mathrm{h}$; $\mathrm{k}$ and $\lambda$ are fitting parameters, the parameters are shown in Table 4.

Table 4 Fitting parameters of sediment of pile-soil

\begin{tabular}{cccccccccc}
\hline \multicolumn{3}{c}{ Fitting parameters of sediment of layer } & \multicolumn{5}{c}{ Fitting parameters of sediment of pile } \\
\hline displacement & $\mathrm{s}_{\mathrm{tm}}$ & $\lambda$ & $\mathrm{k}$ & $\mathrm{R}^{2}$ & Single-pile & $\mathrm{s}_{\mathrm{tm}}$ & $\lambda$ & $\mathrm{k}$ & $\mathrm{R}^{2}$ \\
\hline LVDT8 & 6.548 & 1.1452 & 6.6783 & 0.970 & radius14 & 0.681 & 1.3411 & 5.3414 & 0.982 \\
LVDT7 & 4.137 & 1.5333 & 7.8170 & 0.982 & radius16 & 0.661 & 1.2608 & 5.2349 & 0.982 \\
LVDT6 & 2.729 & 1.4042 & 11.5658 & 0.959 & radius20 & 0.641 & 1.3536 & 5.3880 & 0.983 \\
LVDT5 & 1.351 & 1.0806 & 4.4337 & 0.990 & & & & & \\
LVDT4 & 0.736 & 0.6970 & 1.3162 & 0.868 & & & & & \\
LVDT9 & 0.319 & 9.5573 & 0.5357 & 0.922 & & & & & \\
\hline
\end{tabular}

\subsection{The relationship between axial force of pile and time}

According to the similarity criterion, lateral friction of pile and the axial force of the pile of prototype can be calculated with the Eq. (3) and Eq. (4).

$$
\begin{gathered}
P_{t i}=n^{2} E_{m} A_{m} \varepsilon_{t i} \\
q_{t i}=\Delta P_{t i} / S
\end{gathered}
$$

Where $\mathrm{P}_{\mathrm{ti}}$ is the axial force of I pile, $\mathrm{kN} ; \mathrm{E}_{\mathrm{m}}$ is elasticity modulus of the model pile, $\mathrm{GPa} ; \mathrm{A}_{\mathrm{m}}$ is the sectional area of model pile, $\mathrm{mm} 2 ; \varepsilon_{\mathrm{i}}$ is measured strain value of I model pile; $\Delta \mathrm{P}_{\mathrm{ti}}$ is the 
difference of measured axial force of the cross section of I pile, $\mathrm{kN}$; $\mathrm{S}$ is lateral surface area of measuring section of the pile of prototype, $\mathrm{m}^{2}$.

The axial force of pile shaft is shown as Fig. 5 when it load the loading of $1576.0 \mathrm{kN}, 1260.8 \mathrm{kN}$, $1103.2 \mathrm{kN}$ on the hollow pile of radius of $1.5 \mathrm{~m}, 1.2 \mathrm{~m}, 1.05 \mathrm{~m}$. The lateral friction is shown in Fig. 6 . The length of the pile of prototype is $16.25 \mathrm{~m}$ and the thickness of dredger fill is $6.75 \mathrm{~m}$.
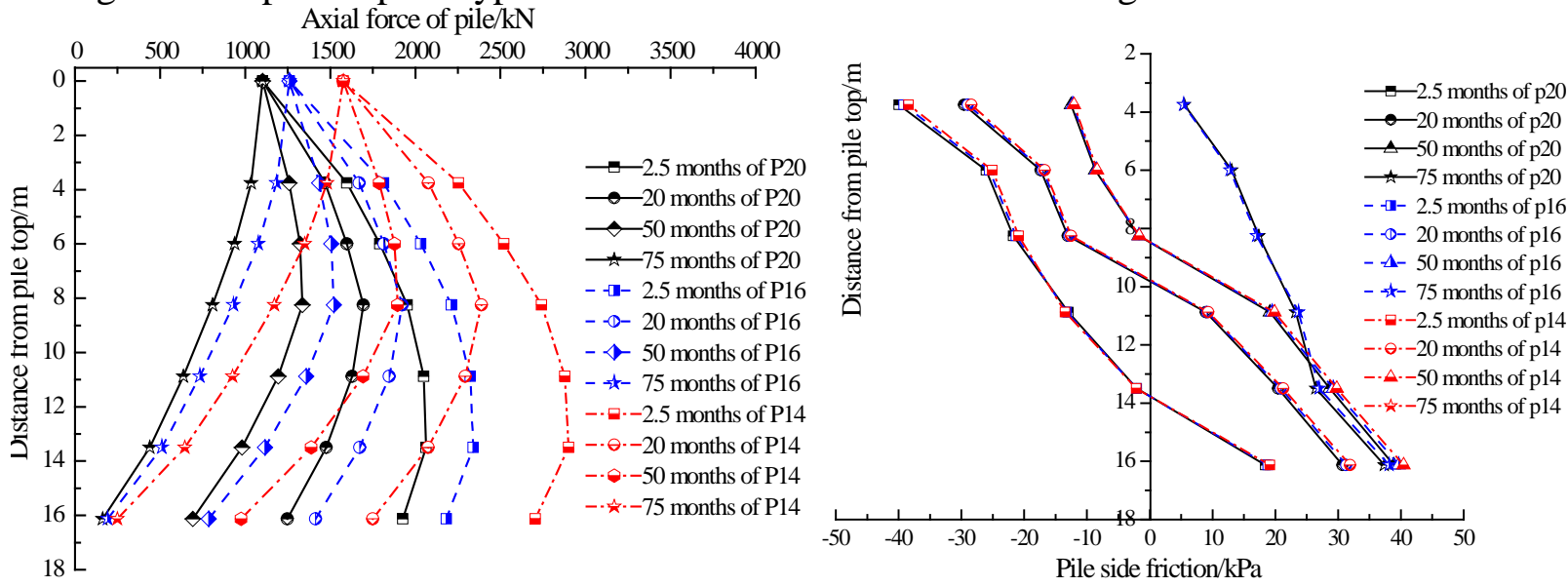

Fig. 5 Relationship between axial force and time Fig. 6 Relationship between lateral friction and time

The negative friction of pile of prototype caused by the self-weight of dredger fill is shown in figure6. According to Fig. 5-6 and Table 5 we can find that the increasing rate of axial force of pile is $85.56 \%, 52.57 \%, 20.65 \%$ as the time of consolidation is 2.5 moths, 20 months, 50 months. Negative friction of single-pile is smaller when the consolidation of dredger fill is longer. All of the friction of pile will become positive when the soil consolidate for 75months.

Table 5 Relationship between maximum friction of pile of prototype and time

\begin{tabular}{|c|c|c|c|c|c|c|}
\hline \multirow[b]{2}{*}{$\begin{array}{l}\text { pile of } \\
\text { prototype } / \mathrm{m}\end{array}$} & \multicolumn{6}{|c|}{ The maximal negative friction $/ \mathrm{kN}$} \\
\hline & 2.5months & $\begin{array}{c}\text { rate of } \\
\text { increase/\% }\end{array}$ & $\begin{array}{c}20 \\
\text { months }\end{array}$ & $\begin{array}{c}\text { rate of } \\
\text { increase } \\
/ \%\end{array}$ & 50months & $\begin{array}{c}\text { rate of } \\
\text { increase } \\
\quad \% \%\end{array}$ \\
\hline 1.05 & 960.75 & $87.09 \%$ & 591.72 & $53.63 \%$ & 232.43 & $21.06 \%$ \\
\hline 1.2 & 1078.58 & $85.54 \%$ & 662.73 & $52.56 \%$ & 260.33 & $20.64 \%$ \\
\hline 1.5 & 1324.44 & $84.03 \%$ & 811.83 & $51.51 \%$ & 318.89 & $20.23 \%$ \\
\hline
\end{tabular}

\section{Conclusion}

(1) When the thickness of the dredger fill in soft foundation is $6.75 \mathrm{~m}$, the negative friction equals to $85.56 \%, 52.657 \%, 20.65 \%$ of the pile top load when the time of self-weight consolidation is 2.5months, 20months, 50months.

(2) The negative friction of the pile foundation decrease with the self-weight consolidation of the dredger fill until it disappears.

(3) The relationship between pile-soil consolidation and time conforms to the Eq. (2), It is feasible to forecast the pile-soil settlement value of the self-weight consolidation of stacking dredger fill in soft soil through this formula.

\section{Acknowledgements}

This investigation was supported by the National Natural Science Foundation of China (projects 
No. 41672274 and 41002093); the Natural science foundation of Shanghai (project No. 14ZR1442800); Opening fund of State Key Laboratory of Geohazard Prevention and Geoenvironment Protection (Chengdu University of Technology) (projects No. SKLGP 2014K013). The authors are extremely grateful for the financial support from these four organizations.

\section{References}

[1] Xiao-yu Bai, Ming-yi ZHANG, Lei ZHU, Yong-hong WANG, Jing-jing WANG. In-situ test and FEM analysis on bearing characters of rock-socketed short pile for highly weathered granite [J]. Journal of Central South University (Science and Technology), 2017, 48(2): 512-524.

[2] Zi-sheng Liu. Field tests on negative skin friction of steel pipe piles in high backfilling soils [J]. Chinese Journal of Geotechnical Engineering, 2015, 37(2): 337-342.

[3] Yi-feng ZHENG, Jian Mao, Shi-zhong Liang, Chuan-feng Zheng. Negative skin friction of pile foundation considering soil consolidation in high fill site [J]. Journal of Jilin University (Engineering and Technology Edition), 2017, 47(4): 1075-1081.

[4] Wenjuan Yao, Yimin Liu, Jun Chen. Characteristics of negative skin friction for superlong piles under surcharge loading [J]. International Journal of Geomechanics, 2012, 12(2): 90-97.

[5 Hyeong Joo Kim, Jose Leo C. Mission. Negative skin friction on piles based on finite strain consolidation theory and the nonlinear load transfer method [J]. KSCE Journal of Civil Engineering, 2009, 13(2):107-115.

[6] Mehmet Ergun, Devrim S. Negative skin friction from surface settlement measurements in model group tests [J]. Can. Geotech. J., 1995, 32: 1075-1079.

[7] Huang Ting, Gong Wei ming, Dai Guo liang, et al. Experimental research of time effect of negative skin friction on pile [J]. Rock and Soil Mechanics, 2013, 34(10):2841-2846.

[8] Leung C F, Liao K, Chow Y K, et al. Behavior of pile subject to negative skin and axial load [J]. Soils and Fundations Japanese Geotechnical Society, 2004, 44(6):17-26.

[9] Lam S Y, Charles W.W. Ng, Leung C F, et al. Centrifuge and numerical modeling of axial load effects on piles in consolidating ground [J]. Can. Geotech. J. 2009, 46: 10-24.

[10] Fellenius B H. Results from long-term measurement in piles of drag load and downdrag [J]. Can. Geotech. J., 2006, 43: 409-430.

[11] Kazem Fakharian, Mahmoud Meskar, Amir S. Mohammadlou. Effect of Surcharge Pressure on Pile Static Axial Load Test Results [J]. Int. J. Geomech., 2014, 14(6): 1-9.

[12] Abdrabbo, Fathi M., Ali, Naema A. Behaviour of single pile in consolidating soil [J]. ALEXANDRIA ENGINEERING JOURNAL, 2015, 54(3): 481-495.

[13] Kong GQ., Zhou Y., Yang Q. Group effect of dragload in pile groups embedded in consolidating soil under embankment load [J]. KSCE JOURNAL OF CIVIL ENGINEERING, 2016, 20(6): 2208-2220.

[14] Hong Y., Ng C. W. W., Chen Y. M., et al. Field Study of Downdrag and Dragload of Bored Piles in Consolidating Ground [J]. JOURNAL OF PERFORMANCE OF CONSTRUCTED FACILITIES, 2016, 30(3): 04015050-1-11.

[15] Yang Ping, Tang Yi-qun, Zhou Nian-qing, et al. Consolidation settlement of Shanghai dredger fill under self-weight using centrifuge modeling test [J]. J. Cent. South Univ. (Science and Technology), 2008, 39(4): 862-867. 